\title{
Consumer food ethics: considerations of vulnerability, suffering, and harm
}

\begin{abstract}
Over the past years, various accounts of ethical consumption have been produced which identify certain concepts as central to mediating the ethical relationship between the consumer and the consumed. Scholars across disciplinary fields have explored how individuals construe their ethical consumption responsibilities and commitments through the notions of identity, taking care and doing good, proximity and distance, suggesting the centrality of these themes to consumer engagement in ethical practices. This paper contributes to the body of research concerned with unravelling consumers' conceptually mediated relationship to moral and ethical issues in the sphere of consumption by revealing a new set of ideas through which people interpret and relate to consumption ethics. Drawing upon findings from an empirical study on self-perceived ethical food consumers, I demonstrate that people's perceptions and views of ethical problems around consumption are bound up with notions of vulnerability, suffering, and harm, and that these notions permeate and impact all aspects of ethical consumer behaviour. The paper concludes by arguing that we need to further explore the conceptual underpinnings of ethical consumer commitments and practices, and expand the conceptual toolkit of research on ethical consumption to account for a wider range of ideas and notions that shape individual as well as collective motivations, intentions, and actions throughout the process of becoming and being an ethical consumer. Finally, the paper suggests a specific analytical framework to facilitate such research.
\end{abstract}

Key words: ethical consumer, consumption ethics, vulnerability, suffering, harm 


\section{Introduction}

The past several decades have witnessed a striking increase in ethical consumption across the world (Shaw, Carrington \& Chatzidakis, 2016). In the UK alone, the value of ethical spending grew to $£ 38$ billion in 2015 , reflecting a continuous rise in ethical buying across a wide range of consumer markets (Ethical Consumer Markets Report, 2016). The growth of individual and collective consumer mobilisation around ethical causes has attracted increasing public, policy, and academic attention, and various aspects of the ethical consumption phenomenon have stimulated debate and discussion among experts in different fields. The figure of the ethical consumer has become a key focus of theoretical and empirical analyses in sociology, geography, psychology, philosophy, economics, advertising and marketing research. In much of the current literature, ethical consumers are broadly defined as individuals who are "concerned with the effects that a purchasing choice has, not only on themselves, but also on the external world around them' (Harrison, Newholm \& Shaw, 2005, p. 2). The generic ethical consumer, assuming there is one, is resistant to more precise definitions. The notion of ethical consumption, as many have noted, is complex and diverse in its performances and understandings: what it means and how it is practised varies individually, socially, and contextually (Littler, 2009). Far from uniform, ethical consumer acts and activities harbour a wide variety of subjective meanings, framings, and narratives. There have been continuous attempts to shed light on the orientations and motivations underlying ethical consumer conduct. Scholars across disciplinary fields have brought a diversity of conceptual lenses to these questions, giving rise to a wide range of perspectives on considerations that motivate, underpin, and direct ethical consumer behaviours and practices.

In sociology, identity has become one of the key conceptual tools for explaining consumer adoption of ethical lifestyles. A large body of research has explored ethical consumers' identity motives and goals, from the pursuit of self-discovery and authentic identity to 'moralselving', i.e. the cultivation of a better personal self through ethical action, to virtue signalling and impression management (Moisander \& Pesonen, 2002; Shaw \& Shiu, 2003; Barnett, Cloke, Clarke \& Malpass, 2005; Newholm, 2005; Cherrier, 2006; Shaw, 2007; Dastrup, Zivin, Costa \& Kahn, 2012). These studies have shown that identity represents a major recurring theme in consumers' narratives about their ethical practices, suggesting its centrality within the set of meanings underpinning individual and collective commitments to ethical lifestyles.

Another prominent notion that informs many first-person accounts of ethical 
consumption and that has become influential in sociological and philosophical analyses of ethical consumer action is that of 'doing good'. Many studies have brought under scrutiny the ideas of 'doing good' or 'doing the right thing' permeating consumers' narratives of their ethical consumption commitments. While some authors appear convinced of other-regarding motives to which ethical consumers lay claim (Shaw, 2007; Varul \& Wilson-Kovacs, 2008; De Groot \& Steg, 2009), others shine a critical light on the assumption of the inherently altruistic ethical consumer by drawing attention to the self-satisfying dimension of ethical purchase and consumption behaviour. In her work on alternative hedonism, the philosopher Kate Soper (2008) theorises the complex form of self-satisfaction derived from consuming differently (see also Gould, 2003; Lekakis, 2013). A number of authors have found a direct link between selfrewarding feelings of 'doing the right thing' and individuals' intentions to consume in an ethical way (Smith, 1990; Zadek, Lingayah \& Forstater, 1998; John, Klein \& Smith, 2002; Arvola et al., 2008), thus shifting the focus from the idea of 'doing good' and 'being good' to that of 'feeling good' in trying to capture the leitmotif of ethical consumer behaviour.

Approaching ethical consumption from socio-cultural, political-economic, or marketing perspectives, these studies fail to engage with a vast body of philosophical knowledge that could aid the development of a more nuanced, fine-grained account of the underlying motives behind consumer engagement in ethical practices. More specifically, there has been very little, if any, attempt to elaborate just what the concept of 'doing good' might involve - which shared meanings and individual interpretations it accommodates and which of them play an especially significant role in propelling consumers into ethical actions. Soper (2008) briefly mentions the notions of damage and harm when discussing the relationship between individuals' beliefs about material culture and their aesthetic responses to it, the main claim being that what people perceive as harmful or damaging - for themselves, other people, or the environment - cannot form a part of their conception of the good life; instead, such goods and commodities inspire presumably hedonistic consumers to adopt increasingly anti-consumerist aesthetic and ethic. Yet, no questions are raised and no discussion ensues about how consumers' commitment to avoiding or minimizing any harm caused to others fits with and feeds into their concept of the good life. This paper seeks to rectify this omission by considering the do-no-harm principle as one prominent conceptual resource whereby consumers make sense of and operationalise the idea of 'doing good' and 'doing the right thing'. 
More recently, scholars in the field of consumer ethics have closely engaged with the conceptual lens offered by care. There is a growing stream of research on the topic that incorporates the notion of care in an effort to provide a more complete account of consumer ethics. Studies that focus on the care dimension of ethical consumption include Shaw, McMaster \& Newholm's (2013) enquiry into the ways in which people understand and articulate an ethics of care in relation to consumption and Heath, O’Malley, Heath \& Story’s (2016) research exploring the impact of caring relationships on ethical consumer attitudes and behaviours. Both studies reveal a complex interaction between care ethics and ethical consumption, arguing for the potential of the philosophy of care ethics (Held, 2006; Timmons, 2002) to provide a more comprehensive framework for understanding ethical consumer discourses and practices and, more specifically, for explaining the seemingly intractable attitude-behaviour gap in ethical consumption.

In human geography, the notions of time and space have become central to investigations into consumption ethics. A large number of geographical studies have applied the conceptual lenses of time and space to analyse the ways in which moral and ethical issues in the consumption domain are mobilised and articulated (Goodman, 2004; Barnett et al., 2005; Jackson, Ward \& Russell, 2009). Stressing that 'care is fundamentally geographical in its production, development, reception and, now, consumption' (McEwan \& Goodman, 2010, p. 109), human geographers have engaged in efforts to illuminate the nature and extent of responsibility and commitment exhibited by ethical consumers through examining the geographies of ethics and care. 'Geographies of responsibility' (Massey, 2004), 'ethics of distance' (Coff, 2006), 'spatial dynamics of concern' (Goodman, 2004, p. 906), 'spatially extensive beneficence' (Smith, 2000, p. 93), 'geographies of regard' (Lee, 2000) are examples of notions that research on the interface of geography and moral philosophy has contributed to the conceptual toolbox of the scholarship on consumption ethics. Following the lead of human geographers, researchers in other fields have used the notions of time and space to explore how individuals develop, interpret, and apply moral responsibility in consumption. While some of this work (Goodman \& Goodman, 2001; Coff, 2006; Bildtgård, 2008;) is theoretical in nature, other studies demonstrate the central role of the ideas of time and space in mediating the ethical relationship between the consumer and the consumed through empirical evidence, such as interviews with food industry actors (Jackson et al., 2009), first-person accounts provided by ethical consumers (Adams \& Raisborough, 2010), semiotic and discursive analyses of ethical 
labelling, packaging, and promotion materials (Goodman, 2004; Barnett et al., 2005).

Regrettably, space limitations do not permit giving due consideration to a full range of ideas and notions that have been applied to the study of ethical consumption by scholars in various disciplines. The above overview, while by no means exhaustive or all inclusive, is intended to illustrate some of the more prominent concepts that, as the academic literature suggests, ethical consumers integrate into their consumption behaviours and attitudes and that define how consumers interpret the meaning of their ethical commitments for themselves and for others. In virtue of being central to the ways in which individuals construe and relate to moral and ethical issues in the realm of consumption, the notions of taking care and doing good, identity and self-view, time and space have become the main axes around which much of the academic discussion of ethical consumption revolves. They, however, do no exhaust the full range of conceptual devices mediating the ethical relationship between consumers and goods. In this paper, I argue that we need to further expand the conceptual toolkit used in the analysis of ethical consumption through exploring what other ideas and notions play a role in informing consumer sense of moral responsibility and directing its course. The present paper contributes to this objective by identifying a new set of concepts via which consumers make sense of and engage with consumption ethics. Drawing on empirical research on self-perceived ethical food consumers, I suggest that vulnerability, suffering, and harm are three prominent concepts through which moral and ethical issues reach modern consumers and which play an important role in shaping ethical consumer motivations, intentions, and actions.

The paper draws extensively on knowledge derived from the fields of moral psychology and moral philosophy. These particular disciplines are highly relevant to research on ethical consumer behaviour, which has distinctive moral and ethical dimensions (De Groot, Thogersen $\&$ Schubert, 2016). As various authors tell us, ethical consumption 'is a complex ethical issue... which involves ethical judgments and disputes...' (Moisander, 2007, p. 4) and which 'seems at least partially founded in moral reasoning or norms' (De Groot, 2016, p. 61). A certain amount of intellectual effort has already gone into the application of philosophical (Barnett, Cafaro \& Newholm, 2005; Coff, 2006; Soper, 2008) and psychological (De Groot, 2016) insights to the academic study of ethical consumption. A growing interest in engaging with questions of morality and ethics characteristic of the 'normative turn' in social sciences and shared by consumer scholars has been celebrated as a right step towards a more sophisticated analysis of a range of long-standing questions about human behaviour. Geographers have especially 
welcomed the blurring of the boundaries between their discipline and the field of ethics, hoping to achieve new levels of sensitivity in considering 'the issues on the interface of geography and moral philosophy' (Smith, 1998a), of which ethical consumption has clearly become a prominent one. By engaging with knowledge drawn from the fields of moral psychology and moral philosophy, I aim not only to build a more comprehensive and nuanced framework for examining ethical consumer behaviour, but also to promote greater interdisciplinary cooperation in exploring the complex phenomenon of ethical consumption, the need for which has been recognised in the most recent literature on the topic (Shaw et al., 2016). In the next section, I clarify the meanings of the key concepts 'harm', 'suffering', and 'vulnerability' as they are generally defined in philosophical literature and as they were interpreted by the research participants. Next, I present the four-component model of moral behaviour put forward by Rest (1994) which I adapt and use as a theoretical framework for analysing ethical consumer conduct.

\section{Conceptual and theoretical framework}

This study focuses on the notions of suffering, vulnerability, and harm as examples of the fundamental concepts that underpin and inform individuals' sense of ethics and moral obligation in relation to consumption. A common philosophical understanding of harm suggests that 'a harmful action, event or condition is what makes a life worse than it would have been otherwise, if that action or event had not occurred, or if that condition was not present' (Kahane \& Savulescu, 2012, p. 319, emphasis in original). This definition closely aligns with the subjects' interpretations of harm which laid emphasis on the modern-day economic system as the key source of harm and a range of morally relevant entities, such as nature, humans, and animals, as its main victims. Moreover, the subjects were clearly inclined towards the expansive idea of harm according to which both an infliction of pain and suffering as well as a deprivation of 'opportunities for doing what will bring satisfaction' (Regan, 1983, p. 303) are classified as harms. In describing their ethical consumer concerns and motivations, none of the interviewees seemed to be guided by the simple meaning of harm as restricted to the experience of physical or emotional pain. In their view, just as much harm could be done through a direct infliction of pain as through a deprivation of fundamental rights and opportunities, such as the right to life (one of the moral principles underpinning vegetarianism and veganism) or an opportunity to participate in society on an equal basis with others (a moral cause at the heart of the fair trade movement). 
In the philosophical literature, suffering is commonly understood as a negative mental state associated with considerable physical discomfort and/or emotional distress (Degrazia, 1998; Aaltola, 2012) and just one among many possible instances of harm. In common parlance, however, the dividing line between harm and suffering may become rather blurred or even disappear altogether, as was the case with my research participants who used these two terms interchangeably. It is noteworthy that while respondents in this study did not distinguish between suffering and harm when trying to conceptualise consumption ethics, the difference between the two notions proved highly relevant in the context of their actual consumption behaviour. For instance, some of the vegans and vegetarians I interviewed refrained from consuming animal products to avoid contributing to the suffering of animals treated with cruelty on factory farms, but would be content with eating meat from humanely raised and killed animals - such was the view expressed by Lucy, Solveig, Manasi. Their example demonstrates that it is possible for people to commit to reducing the suffering of others while being prepared to cause these same others the ultimate harm (for, of course, death harms sentient beings by depriving them of the opportunity to live a happy life).

Finally, the respondents' interpretations of the concept of vulnerability aligned with a widely-held understanding of vulnerability as the state of affairs in which someone or something is at risk of harm or especially susceptible to it (Goodin, 1986). Their ethical consumption intentions and actions, however, were guided by considerations of a particular type of vulnerability, namely that which arises from harms that come about through the choices people make in their capacity as consumers. The idea of vulnerability employed by the subjects is also distinctly relational, for it implies the presence of a moral agent - a consumer - at whose discretion harm may be caused or averted, and morally relevant entities - people, other sentient creatures, the planet - that are at risk of being injured or harmed.

I analysed the role of the notions of vulnerability, suffering, and harm in informing ethical consumer attitudes and behaviours through the lens provided by the psychological model of moral behaviour developed by Rest (1994). According to it, there are four key aspects to human morality: moral sensitivity, which refers to people's awareness of the moral implications of their actions; moral judgment, which requires a person to determine whether an action is morally right or wrong; moral motivation, which concerns the willingness to prioritise moral values and principles over other considerations; and moral character, which translates into perseverance in maintaining a moral commitment. Assuming that ethical food consumption is a 
form of moral conduct (which any intentional, conscious, and value-oriented act of ethical consumption surely is), Rest's model allows us to identify and consider the main elements and prerequisites of ethical consumption behaviour. Indeed, it seems evident that the adoption of ethical modes of consumption requires the presence of all four components suggested by Rest: awareness of consumption-related ethical problems and a sense of responsibility and concern for the wider social, environmental, and moral impacts of one's own ways of consuming (moral sensitivity); decision-making about the moral validity of specific consumption acts and activities (moral judgment); willingness to prioritise ethical motives over other often competing desires and needs (moral motivation); and, finally, the ability to sustain commitment to ethical practices over time (moral character).

A detailed analysis of the personal narratives, thoughts, and reflections shared by the participants confirmed the empirical relevance of Rest's model and its potential to yield a much more nuanced understanding of ethical consumption behaviour by enabling the researcher to disentangle and more closely explore its different components. In the present study, I apply a slightly modified version of Rest's original model, as I found that individuals' willingness to prioritise ethical concerns over many other considerations which may influence their consumption decisions (indispensable to consumer adoption of ethical practices) and their persistence in sustaining a morally conscious lifestyle are so closely intertwined that are best considered in tandem. The decision to merge these two dimensions of ethical consumer behaviour into one category has been made in the context of an acknowledged need to distinguish motivation for individuals to engage in ethical consumption from that which makes already committed consumers persevere in their pursuit of ethical living, as the two types of motivation may originate from different places. That said, my analysis of participants' narratives collected using formal and informal interviews has identified the notions of suffering, vulnerability, and harm as having a role in both arousing and maintaining people's sense of concern, responsibility, and commitment with regard to the ethical issues behind their consumption behaviour. The respondents appealed to these ideas when recounting their experiences of becoming as well as being ethical consumers, suggesting that motivation for both was derived from the same or very similar conceptual sources. This evidence provided the rationale for merging the last two components of Rest's model - moral motivation and moral character - into one category. It is, however, possible that future research into ethical consumer conduct will supply evidence necessitating a clear distinction between the two. 
My final analytical framework, therefore, comprises three distinct categories: 'ethical sensitivity', 'ethical judgement and decision-making', and 'ethical commitment and motivation'. These categories serve as thematic headings under which my research findings are grouped.

\section{Method}

The present study arose from a more comprehensive research project on ethical consumer practices and identities in which ten self-perceived ethical food consumers from the North of England (four males and six females between 29 and 64 years old) took part. My key criterion in selecting participants was their sense of self as ethical subjects, that ethical is "a fundamental part of who they are, how they think and feel, and ultimately affects how they consume" (Connolly and Prothero, 2008, p. 123). I used a purposive sample comprising a small number of information-rich cases in order to get the best information from people most likely to have the experience to provide valuable insights on the research topic (Patton, 2001; Denscombe, 2014). The project was advertised via posters and flyers distributed in ethically oriented places and sites such as natural food shops, vegetarian/vegan eating establishments, and ecological housing developments. This was considered a legitimate way to access ethical consumers because, drawing on Archer's arguments that "subjects acquire their personal identities through the constellation of concerns that they endorse" (2012, p. 22) and that "it is not possible to have a genuine concern and to do nothing about it" (2007, p. 231), I assumed that self-identities of ethical consumers must be tied to concerns about the moral, environmental, and social implications of their lifestyle choices and that these concerns must translate into concrete actions, i.e. decisions about where to buy groceries, where to eat, and where to live. This recruitment technique has been successful in attracting a sufficient number of respondents, whose main characteristics are summarised in Table 1. As Table 1 shows, most of the study subjects, although not all, were either vegans or vegetarians; among respondents there were five consumers committed to eating organically and five regular buyers of fair trade products. While research participants shared many similarities in terms of their consumption practices, their behaviours had different, although often overlapping, ideological underpinnings, including condemnation of the killing of animals, promotion of animal welfare, respect for the environment, commitment to social justice and human rights. Thus, despite its limited size, the sample was sufficiently diverse to provide insight into a wide range of moral concerns, motivations, and meanings underlying ethical purchase and consumption behaviour. 
Table 1. Main characteristics of the study participants

\begin{tabular}{|c|c|c|c|c|}
\hline Pseudonym & Sex and age & Occupation & Ethical practice & Ethical concerns \\
\hline David & Male, 33 & PhD student & $\begin{array}{l}\text { Vegetarian } \\
\text { Consumer of organic, } \\
\text { local, and fair trade } \\
\text { products }\end{array}$ & $\begin{array}{l}\text { Environment and } \\
\text { climate change } \\
\text { Social justice and } \\
\text { human rights } \\
\text { Animal welfare }\end{array}$ \\
\hline Darren & Male, 36 & Activist & Vegan & $\begin{array}{l}\text { Animal life and } \\
\text { welfare }\end{array}$ \\
\hline Lucy & Female, 48 & $\begin{array}{l}\text { Occupational } \\
\text { therapist }\end{array}$ & Vegetarian & $\begin{array}{l}\text { Animal life and } \\
\text { welfare }\end{array}$ \\
\hline Solveig & Female, 29 & PhD student & Vegan & $\begin{array}{l}\text { Animal life and } \\
\text { welfare }\end{array}$ \\
\hline Mary & Female, 64 & Retired & $\begin{array}{l}\text { Consumer of organic, } \\
\text { local, and fair trade } \\
\text { products }\end{array}$ & $\begin{array}{l}\text { Environment and } \\
\text { climate change } \\
\text { Social justice and } \\
\text { human rights } \\
\text { Animal welfare }\end{array}$ \\
\hline Maggi & Female, 62 & Retired & $\begin{array}{l}\text { Vegan } \\
\text { Consumer of organic, } \\
\text { local, and fair trade } \\
\text { products }\end{array}$ & $\begin{array}{l}\text { Animal life and } \\
\text { welfare } \\
\text { Environment and } \\
\text { climate change } \\
\text { Social justice and } \\
\text { human rights }\end{array}$ \\
\hline Manasi & Female, 31 & Engineer & $\begin{array}{l}\text { Vegetarian } \\
\text { Consumer of organic } \\
\text { and local products }\end{array}$ & $\begin{array}{l}\text { Environment and } \\
\text { climate change } \\
\text { Social justice and } \\
\text { human rights }\end{array}$ \\
\hline Joe & Male, 29 & $\begin{array}{l}\text { Call centre } \\
\text { agent }\end{array}$ & $\begin{array}{l}\text { Vegan } \\
\text { Consumer of local } \\
\text { products }\end{array}$ & $\begin{array}{l}\text { Animal life and } \\
\text { welfare } \\
\text { Environment and }\end{array}$ \\
\hline
\end{tabular}




\begin{tabular}{|c|c|c|c|c|}
\hline & & & & $\begin{array}{l}\text { climate change } \\
\text { Social justice and } \\
\text { human rights }\end{array}$ \\
\hline Lila & Female, 34 & Editor & $\begin{array}{l}\text { Vegan } \\
\text { Consumer of organic, } \\
\text { local, and fair trade } \\
\text { products }\end{array}$ & $\begin{array}{l}\text { Animal life and } \\
\text { welfare } \\
\text { Environment and } \\
\text { climate change } \\
\text { Social justice and } \\
\text { human rights }\end{array}$ \\
\hline
\end{tabular}

The data on which this paper draws comes from detailed case studies informed by extensive observational and field notes which ensued from a series of accompanied shopping trips and informal discussions with each participant, verbatim transcriptions of interview data, and any other documents and materials that generated insights into the subjects' understandings and performances of ethical consumption (e.g. unsolicited food diary). Here I focus on nine out of ten cases and make selective use of the data, drawing primarily on the formal interviews and focusing on the narratives that most effectively illustrate my main arguments. The interviews were informed by a combination of life history and hermeneutic phenomenological approaches and ranged in length from two to five hours. During the first part of the interview, the respondents were asked to tell their life stories focusing specifically on their earliest food memories, their family's and, subsequently, their own shopping, cooking, and eating practices and the evolution thereof over time. The purpose was to contextualise the subjects' ideas and practices of ethical consumption within their personal life histories. In the second part of the interview, participants were invited to share their views and feelings in relation to ethical consumption in general and their own ethical commitments in particular. Specific questions were used to orient the interviewees towards reflections on the relationship between consumption and ethics and the ways in which they experience moral responsibility as consumers. Consistent with the study's aim to explore the meanings of ethical consumption through the interpretations of those who enact it, I adopted a hermeneutic phenomenological approach to data analysis (Thompson et al., 1994). The analytical process was therefore aimed at revealing structures and relations of meanings that were captured yet not directly observable 
in the data; it involved iterative readings of the text and on-going revisions of prior interpretations and continued until theoretical saturation was reached.

In what follows, I present my findings on the relevance and significance of the notions of vulnerability, suffering, and harm for informing ethical consumer attitudes and behaviours. Thinking in terms of the categories drawn from Rest's model of moral conduct, I demonstrate how these notions contribute to the working up of consumer sense of responsibility and ethics, how they inform consumers' ethical reasoning and decision-making, and, finally, how they mediate people's sense of commitment to consuming in a morally responsible way.

\section{Ethical sensitivity}

Consistent with the findings from previous research (Adams \& Raisborough, 2010; Littler, 2009), this study revealed a diversity in the subjects' views and ideas about ethical consumption. Yet, within and across these different understandings, certain notions stood out as central to consumers' commitments to ethical practices. Specifically, the respondents recurrently talked about being ethical and taking moral responsibility in consumption in terms of avoiding causing suffering or harm. Here I consider examples of subjective framing of consumption ethics via these notions and explore their role in arousing ethical consumer sensitivities and concerns.

Solveig is a telling example of a morally concerned individual with an expansive view of consumption ethics: she has a strong commitment to a vegan diet, supports the animal rights movement, buys most of her clothes from charity shops, and practices 'freeganism'. Solveig's idea of ethical consumption is indelibly linked to the notion of harm: 'do no harm or do as little harm as possible' is how she defines the essence of ethical living, and her view of herself as an ethical consumer is underpinned by continuous efforts to live in accordance with this moral principle: 'for me it is an ethical obligation not to harm where I don't have to harm'. The idea of suffering has been critical to the working up of Solveig's sense of consumption ethics. She developed acute awareness of moral and ethical issues around meat eating through engagement with the narratives of animal suffering that she watched unfold in a Hollywood movie Avatar (Avatar, 2009). The scene in the movie in which the central character, Princess Yue, kneels to apologise to an animal she has killed sensitised Solveig to the ethical implications of her own consumption decisions: 'she [Princess Yue] has respect for the animals and for other sentient creatures, and if I have the same respect I wouldn't eat or consume any products that put other sentient creatures through such treatment and torture'. 
Solveig's pathway to ethical consumption parallels the experience of Maggi, whose lifelong commitment to a meat-free diet is grounded in the sense of moral responsibility for the suffering of animals: 'it was about animals suffering and being killed so that we could eat them'. This comment reveals that Maggi engaged with the ethical aspects of food consumption via the concept of suffering and, more specifically, through direct juxtaposition of animal suffering and the satisfaction of human desires. Maggi's sentiments are echoed by Lucy, who also construes ethical consumption in terms of harm-free and cruelty-free choices and has been a strict vegetarian for more than three decades. Like Maggi, Lucy problematizes the morality of the modern food industry and questions the ethics of the human-nature relationship through the notion of harm: 'all that thing about factory farming just seems harm, what we are doing is enslaving the animals so that we can have something tasty on our plate'. Another example of the relevance of the notions of suffering and harm to consumer engagement with the moral side of consumption is provided by Darren, a committed vegan and fervent animal rights activist. Among all respondents, Darren appears to be the most socially active and visible ethical consumer: he runs a charitable organization which promotes veganism, manages an allotment collective to grow food for the homeless, organizes vegan cooking events to feed those in need, and participates in various vegan public outreach activities. Darren too interprets consumption ethics and his moral duties as a consumer through the notion of suffering: "eliminating the suffering, you know, that is number one of what is ethical', he asserts. In Darren's case, the moral relevance of animal suffering has emanated from a rather peculiar experience - acute physical pain caused by a piece of meat which got stuck between his teeth. As Darren explains, his own discomfort sensitised him to the suffering of others:

I don't want to feel pain, I want to feel as less pain as possible, I want to be pain-free, suffering-free. So then you link that to the wider world, to others, you think about people - what about their pain, other people's pain and other animals' pain, and these things link, connect...

By projecting his painful experience onto other sentient beings, Darren came to embrace the moral obligation to consider and take responsibility for the suffering of all living beings: 'eliminating the suffering, taking it out of your life, removing it' has become the key principle of his approach to consumption. Aspiration for cruelty-free, harmless living has been guiding Darren's progressive engagement with consumption ethics: having initially adopted the 
pescetarian diet, he subsequently transitioned to vegetarianism, before finally committing himself to the vegan lifestyle. Darren's idea and practice of ethical consumption therefore evolved in tandem with his expanding conception of what suffering means and whose suffering he is responsible for through his day-to-day consumption decisions: 'the change came when I went deeper into it ... you look at the treatment of animals - even for the eggs and even for the milk ... the majority of that is unethical'. Similarly, Solveig's sense of moral responsibility for the life and wellbeing of all sentient creatures has emerged and developed through identification with animals and their suffering:

(...) as a human being am I really that separate from a chimpanzee? And if I am not, how am I... I am only separated by degrees from, say, a pig or a cow and how... if I don't have to eat these products to survive, how can I justify putting other sentient creatures though treatment like this?

As the above comments suggest, participants' intuitions about the moral responsibilities that as humans and, more specifically, as consumers they have towards other sentient beings are guided by the notions of suffering and harm. This finding supports the relationship between appropriation of others' suffering and the formation of moral character theorised by identity scholars and moral psychologists alike. Thus, Lawler (2008, p. 24) suggests that 'empathetic understanding', i.e. identification with the pain and suffering of others, is highly consequential for individuals' formation as ethical subjects. In moral psychology, the capacity for taking up the place of another is referred to as empathetic imagination and considered to be a pre-requisite for the development of moral sensitivity (Johnson, 1993; Stueber, 2016). These theoretical insights provide a useful prism through which to consider the empirical examples presented above. Darren's experience can be construed as an 'imaginative encounter' (Stueber, 2016, p. 199) with the suffering of other sentient creatures; this imaginative encounter, as Darren himself indicates, played a key role in arousing his ethical sensitivities and concerns: 'it made me think about the pain that is caused to animals'. This is a prime example of 'imaginative empathetic projection' (Johnson, 1993, p. 199) the capacity for which is considered to be central to human morality. Likewise, Solveig's comment reveals a deliberate and highly reflexive attempt to identify with other sentient beings and relate to their conditions and states. Through this ‘imaginative exploration' (Johnson, 1993, p. 200) Solveig has come to embrace the otherregarding perspective and assume moral responsibility for the wellbeing of suffering others. 
These findings shine a new light on the role of physical proximity in fostering human morality, a question on which some strongly contrasting views have been expressed in the past. Bauman (1989, p. 192), for example, insists on the importance of closeness in enabling and encouraging moral conduct:

Morality seems to conform to the law of optical perspective. It looms large and thick close to the eye. With the growth of distance, responsibility for the other shrivels, moral dimensions of the object blur, till both reach the vanishing point and disappear from view.

Vetlesen (1993), on the other hand, challenges the assumption that there is a necessary link between physical proximity and moral behaviour arguing that proximity makes a moral difference only through interaction with other factors. What is crucial, he claims, is 'the capacity for developing empathy with others ... the faculty that underlies and so facilitates the entire series of specific, manifest emotional attitudes and ties to others, such as love, sympathy, compassion, or care' (Vetlesen, 1993, p. 381, emphasis in original). The present study provides relevant empirical evidence to inform this debate. My analysis of ethical consumers' personal narratives suggests that the sense of care and responsibility for the other, 'this building block of all moral behaviour' (Bauman, 1989, p. 184), can be triggered through various ways which do not necessarily meet the criterion of physical closeness. Indeed, we have seen how in Darren's case the moral urge followed the projection of his physical pain onto other sentient beings: 'then you link that to the wider world, to others' and appropriation of their suffering: 'what about their pain?'; and how for Solveig it has arisen through self-identification with animals: 'I am only separated by degrees from, say, a pig or a cow... How can I justify putting other sentient creatures though treatment like this?'. The importance of the relational dimension of moral action underscored by Vetlesen manifests itself in the way in which the respondents articulate the sense of moral obligation in consumption via the narratives emphasising commitment to 'doing no harm' and 'causing no suffering' to others. This clearly reveals meaningful connections between the participants and the objects of their moral concerns. In the examples above, however, these connections have been fostered through compression of cognitive rather than physical distance, through empathic understanding, imagination, and identification with others - absent or present, distant or close - for whom moral responsibility is assumed and exercised via forms of ethical consumption. 


\section{Ethical judgement and decision-making}

In this section, I continue to explore first-person accounts of ethical consumption; my aim here is to illustrate how the notions of vulnerability, suffering, and harm inform consumer moral reasoning and decision-making. Participants' comments are useful in drawing attention to the important role of these notions in consumer judgments about what constitutes an ethical product choice. It is reflected, for example, in Darren's approach to evaluating the moral acceptability of his consumption behaviour: 'from a vegan point of view you draw an important line on suffering'. In the same way, considerations of suffering define the boundaries of Solveig's concerns over consumption ethics: 'the whole business of having a central nervous system is really where I sort of draw the line when eating or consuming stuff'. Likewise, for David, a selfdescribed environmentalist whose commitment to ethical living is rooted in strong beliefs in environmental and social justice, an ethical product choice is that which causes the least harm. 'It was only a couple of years ago that I actually got round to checking what the least harmful, the least impactful sugar is', explained David his preference for a particular brand of sugar, spotlighting harmfulness as a key guiding principle of his consumption practices. Lucy's idea of ethical products is also closely linked to the notion of harm: 'the reason why I eat eggs', she explains, 'I've seen those chickens, it's not doing them any harm laying those eggs'. Similarly, considerations of harm underpin Solveig's approach to resolving ethical consumption dilemmas that arise at the dining table. In the first example, Solveig agrees to taste the cheesecake baked by her elderly grandmother thereby violating her commitment to veganism; in the second, she sets aside her vegetarian principles to eat a seafood dinner cooked by her Nigerian hosts. The notion of harm takes centre stage in Solveig's defence of the moral validity of her actions:

I think in a way it is the whole Hippocratic thing, you know, first do not do harm. I know that if I had gone to my grandmother's place and refused the cheesecake that she bought especially because I was coming to visit, I think it would have been more harmful. (...) And Nigeria - it is a similar thing, but on a larger scale, I think.

This suggests that for Solveig the idea of harm has a key relevance in evaluating the morality of her consumption acts and activities. Solveig's subjective understanding of what constitutes harm and whose feelings and wellbeing should be protected from damage informs her specific ethical evaluations and judgments: 'the priority in this case was really not to hurt people's feelings and not to offend people'. As this comment reveals, Solveig's reasoning and 
decision-making about consumption ethics involves priority setting, a process informed by what can be described as a 'hierarchy of vulnerability'. This subjectively developed idea of who is most liable to suffering and who should therefore be prioritised as the object of ethical considerations is highly consequential for how Solveig construes her moral duties in relation to others:

If it was my uncle with the cheesecake, I would not have eaten it (...) I would have been more happy to criticize him for not paying attention to what I eat or not eat, because I know that he could take it (...) she [grandmother] would be a lot more vulnerable for my criticism than my uncle would have been.

The hierarchical approach to assuming moral responsibility in consumption is followed by Darren: 'you want to eliminate the suffering of those who are in the most pain, in the worst position'. These examples make clear that the subjects' consumption strategy is informed by the 'ethics of partiality' premised on the idea that certain groups deserve more consideration and care than others (Smith, 1998b). In a paper on the moral economy of fair trade, Goodman (2004) discusses how the ethics of partiality is exemplified in the moral geography of the fair trade movement, which thrives on the assumption that we ought to help distant farmers and growing communities in poor parts of the world. My findings supports Goodman's insight into the role of the ethics of partiality in defining the ethical consumer agenda; I do, however, escape the conclusion that consumer ethics are always and necessarily informed by the spatial logic (e.g. improving the livelihood of 'distant others' or, conversely, those who 'are closer to home'). While Solveig's prioritisation of her grandmother's feelings can be construed as a clear manifestation of the ethics of closeness, i.e. taking care of the nearest, this approach is not followed through when applied to her uncle. Solveig's unequal treatment of those who are equally close to her is based on her subjective evaluation of their different, in her view, levels of vulnerability and ability 'to take it'. Likewise, Darren's ethical emphasis on the suffering of non-human animals emanates from his feeling of moral obligation to take care of those 'who are in the most pain'. The respondents' practice of partiality is therefore infused with the ethics of justice, for it relates the capacity to care to the need for care by considering inequalities that exist prior to ethical action (see Smith, 1998b), such as differing levels of suffering and susceptibility to harm. Informed by considerations of vulnerability, suffering, and harm rather than space and place, ethical consumer practices escape the inherent defects of the ethics of 
partiality such as parochialism and perpetuation of patterns of unequal well-being (see Friedman, 1991 for a more comprehensive discussion of the ethics of partiality).

The above analysis illustrates how individuals engage in moral reasoning and accomplish ethical decision-making with regard to consumption through recourse to the notions of vulnerability, suffering, and harm. As participants' comments suggest, ethically minded consumers tend to assess the moral validity of their purchase and consumption decisions by considering whether they will inflict suffering on others as well as which others are most vulnerable and should therefore be regarded as primary objects of ethical concerns and considerations. These subjective perceptions and evaluations of others' suffering and vulnerability constitute important criteria against which the morality of specific consumption choices is evaluated and decisions regarding the most ethical courses of action are made by consumers.

\section{Ethical commitment and motivation}

Prior research has shed light on a wide range of economic and structural barriers, such as product price and availability, which affect the extent and persistence of consumer commitments to ethical practices (see Adams \& Raisborough, 2010; Bekin, Carrigan \& Szmigin, 2006). Moving away from this well-explored territory, here I focus on the conceptual underpinnings of ethical consumer intentions and actions and their role in mediating consumer sense of moral responsibility. More specifically, I consider examples of expressions of motivation and commitment in ethical consumption through the notion of harm.

Harm was a recurring theme of importance in the discussions centring on the respondents' motivation to persevere in their pursuit of ethical living. Instructive is an example of Joe, whose commitment to veganism is motivated by a desire to minimise the harmful effects of his dietary and lifestyle choices on the environment, animals, and wider society. Like other respondents, Joe uses harm as a yardstick for measuring the ethical content of his consumption decisions, yet he engages with the notion of harm in a distinct way. Joe translates the impalpable idea of harm into something specific and tangible by quantifying the harmful impact of various consumption choices which he faces and contemplates. For instance, he calculates his personal carbon footprint, thereby putting the indefinitely abstract concept of harm into a concrete form of numbers. Operationalised in this way, the idea of harm provides Joe with a more concrete and reliable guide to less harmful dietary and lifestyle choices thereby facilitating his pursuit of 
ethical consumption. On the other hand, however, it becomes more challenging for Joe to sustain his commitment to harm-free consumption in cases where harm is not easily quantifiable, as revealed in his explanation for why he finds it hard to resist an occasional non-vegan treat: 'it is very hard to quantify what is real harm in me having a fried egg as opposed to beans on toast for dinner this evening'. This comment demonstrates how on one hand the idea of harm motivates Joe to seek out more ethical consumption solutions, while on the other hand its abstractness and impalpability works to diffuse his sense of a morally responsible choice.

Many more examples abound of the ways in which consumers' moral motivation, that is their willingness to prioritise an ethical choice over other desires and needs, is tied up with considerations of harm. This relationship is well-illustrated by Lila, who refers to the notion of harm when constructing an excuse for treating herself to a non-vegan sweet: 'after 15 years of being vegan, I thought - it wouldn't harm, it won't do any harm, I'll just try because I feel like it'. Similarly, David's sense of moral responsibility for the choices that fall outside the parameters of ethical consumption is proportionate to his subjective perception of their harmful effects:

In the grand scheme of things whether you buy an organic apple or a non-organic apple the difference is so tiny that if you are going to feel bad about it, it should be a tiny tiny amount of badness that you feel, equivalent to the difference that is actually going on.

To take another example, Mary, a devoted environmentalist, alludes to the idea of harm when discussing the drivers behind her commitment to consuming organic and locally grown produce:

I don't want myself or people I love to be affected by climate change any more that I want other people around the world to be affected by climate change, because I think it is going to be a major disaster in all sorts of ways.

The respondents' accounts of their continuous efforts (as well as occasional failures) to maintain a coherent ethical lifestyle indicate that consumer sense of motivation and commitment to morally responsible practices is bound up with the idea of harm. As revealed in the comments above, the subjects' persistence in seeking out more ethical consumption solutions is fuelled by a desire to minimise the amount of harm inflicted on others, whether distant or close. The relevance of the notion of harm to consumer sense of moral responsibility becomes apparent 
upon closer scrutiny of participants' justifications of their occasional ethical slip-ups, constructed through reference to the negligible amount of harm they presumably cause.

The respondents' views on factory farming further underscore the importance of suffering in motivating consumers to commit themselves to ethical purchase and consumption behaviours. The majority of interviewees indicated inhumane treatment of animals as a major ethical problem associated with meat eating. Strong emotion words such as 'cruel', 'sadistic', and 'torture' defined the tone of participants' commentaries on the modern animal agriculture highlighting the powerful emotional charge of the notion of suffering. These sentiments was shared by both meat eaters and strict vegetarians and vegans alike who, perhaps somewhat surprisingly, aligned with the view that animal killing was morally acceptable as long as no suffering was inflicted on animals during their life and at the moment of death. Such was the position of Manasi, a life-long vegetarian: 'I don't like the factory farms, but I'm not really against a local farmer who raises cows, they hang out in the pasture, eventually they get killed for meat, but they've had a decent life'. Her attitude is echoed closely by Mary, best described as a vegetarian-oriented omnivore: 'I am okay with free-range animals that had a reasonable life and are killed humanly, and I am not okay with intensively reared animals because it is their lives, it is their experience'. David, who gave up meat on environmental grounds and is not opposed to animal killing per se, also condemns the industrial system of meat production for the cruel treatment of animals; while Lucy, one of the most committed and stringent vegetarians among the respondents, goes as far as to claim that: 'if I was living out in the country side, on my own, on a small holding or something, I wouldn't be a vegetarian, of course I wouldn't be a vegetarian'. These comments highlight the centrality of the notions of suffering and harm to the interpellation of a morally responsible consumer. In light of this evidence, exploring how people construct and apply their views of suffering in the realm of consumption may offer a clue to better understanding individual approaches to ethical consumption and their conceptual underpinnings.

Overall, the empirical evidence presented in the paper suggests that consumers relate to moral issues in consumption and negotiate the call for an ethical choice through the notions of vulnerability, suffering, and harm. Considering how these concepts interact with other ideas informing ethical consumer intentions and attitudes (identity and self-image, taking care and doing good, helping close and distant others) and how such conceptual interweavings may affect individual and collective practices of ethical consumption may be the next step in elaborating 
the theory of ethical consumer behaviour.

\section{Conclusion}

This paper contributes to a body of work that explores the conceptually mediated relationship between individuals and consumption ethics. Its aim was to broaden the current perspective on the spectrum of conceptual devices used by people to make sense of the ethics of consumption and negotiate the complex moral dilemmas they face in their capacity as consumers. Based on the findings from a qualitative sociological study on self-perceived ethical food consumers, I argue for the centrality of the notions of vulnerability, suffering, and harm to the ways in which individuals conceive of an ethical choice and interpret moral responsibility in consumption. Specific examples have been provided to show that the hold of these notions as conceptual means through which people relate to moral and ethical issues in the realm of consumption has a broad reach and permeates in all aspects of ethical consumer behaviour, from cultivation of ethical sensitivities and concerns, to moral reasoning and decision-making with respect to consumption choices, to maintaining motivation and commitment to ethical practices. By illuminating how the notions of vulnerability, suffering, and harm feed into and inform consumer decision-making about the morality of specific acts of consumption, this paper provides an insight into conceptual mediation of ethical consumption. This allows us not only to identify some of the key ideas and meanings which instigate and inform consumer sense of moral responsibility, but also to understand how they shape the development of new and alternative forms of consumer behaviour.

The present study focuses on one particular form of ethical consumption, namely ethical eating, and is therefore limited in its ability to capture the totality of the complex web of orientations and motivations underpinning ethical consumer commitments and practices. The notions of vulnerability, suffering, and harm explored in this paper represent only a small subset of conceptual tools by which consumers interact with ethical demands and ideas of moral responsibility circulating in the sphere of consumption. While these notions appear to be most prominent in the minds of the ethical consumers interviewed for this study, there are undoubtedly many other meanings underlying individual and collective commitments to ethical consumption that are not discussed here and that future research will hopefully bring to light.

While the arguments advanced in this paper should be considered in the context of an acknowledged need for more qualitative research into the concepts and categories underpinning 
ethical consumer intentions and actions, the empirical evidence presented here suggests very clearly that we should make a wider range of notions the object of analysis in exploring consumption ethics. To expand the conceptual lens through which social science researchers have become accustomed to view the subjective meanings and motivations attached to ethical consumer behaviours and thereby achieve a new level of sensitivity in understanding ethical consumption practices, we must be prepared to leave the comfort of close-to-heart disciplines and engage with other domains of knowledge that hold the potential to offer valuable insights about consumption ethics. More specifically, there is a need for closer cooperation between the fields of human geography, sociology, moral philosophy, and moral psychology in the study of the ethical consumption phenomenon. We need to consider how appropriate such interdisciplinary insights may be when applied to ethical consumer behaviour, and what they can tell us about the forging and mediation of the ethical connections between the consumer and the consumed. My application of Rest's model of moral conduct in the present study reflects precisely such efforts, and I hope it can provide future inquirers into the topic with a framework that enables a more sophisticated analysis of ethical consumer behaviour through the exploration of its essential components.

Finally, concern with internally derived motivations and subjectively construed meanings underlying individual ethical consumer behaviours should not distract us from the fact that ethical consumption is a fundamentally social and socially embedded phenomenon. The adoption of ethical practices usually reflects consumers' concerns with the impact of their lifestyles on other people, non-human animals, and the environment - its scope, therefore, extends beyond individual morality to collective-oriented morality (De Groot et al., 2016). The well-recognised importance of social contexts, networks, and relationships in shaping individual consumer discourses and practices calls for an exploration of meso- and macro-contextual influences that operate at a societal level and have potential to structure ethical consumers' thoughts, concerns, and behaviours by directing the course of their mental attention and defining the frontiers of their moral horizons. For instance, through exploring marketplace ideologies and sociocultural discourses (see Gopaldas, 2014), we can shed light on the ways in which ethical and moral issues are constructed and articulated in the consumption domain before being taken up by consumers. In light of the above, it is my hope that this paper will encourage future research to further expand the conceptual, disciplinary, and contextual grounds upon which to explore individual and collective engagement with the idea and practice of ethical consumption. 


\section{References}

Aaltola, E. (2012). Animal Suffering: Philosophy and Culture. Basingstoke: Palgrave Macmillan.

Adams, M., \& Raisborough, J. (2010). Making a difference: ethical consumption and the everyday. The British Journal of Sociology, 61(2), 256-274.

Archer, M. (2007). Making Our Way through the World. Cambridge, UK: Cambridge University Press.

Archer, M. (2012). The Reflexive Imperative in Late Modernity. Cambridge: Cambridge University Press.

Arvola, A., Vassallo, M., Dean, M., Lampila, P., Saba, A., Lähteenmäki, L., \& Shepherd, R. (2008). Predicting intentions to purchase organic food: The role of affective and moral attitudes in the Theory of Planned Behaviour. Appetite, 50(2-3), 443-454.

Avatar. (2009). [DVD] Hollywood: Twentieth Century Fox.

Barnett, C., Cafaro, P., \& Newholm, T. (2005). Philosophy and ethical consumption. In: R. Harrison, T. Newholm \& D. Shaw (Eds.), The Ethical Consumer, (pp. 11-24). London: Sage.

Barnett, C., Cloke, P., Clarke, N., \& Malpass, A. (2005). Consuming ethics: Articulating the subjects and spaces of ethical consumption. Antipode, 37(1), 23-45.

Bauman, Z. (1989). Modernity and the Holocaust. Ithaca, N.Y.: Cornell University Press.

Bekin, C., Carrigan, M., and Szmigin, I. (2006). Empowerment, waste and new consumption communities. International Journal of Sociology and Social Policy, 26(1/2), 32-47.

BildtgÅrd, T. (2008). Trust in food in modern and late-modern societies. Social Science Information, 47(1), 99-128.

Cherrier, H. (2006). Consumer identity and moral obligations in non-plastic bag consumption: a dialectical perspective. International Journal of Consumer Studies, 30(5), 515523.

Coff, C. (2006). The Taste for Ethics: An Ethic of Food Consumption. Springer Science \& Business Media.

Connolly, J. \& Prothero, A. (2008). Green consumption: Life-politics, risk and contradictions. Journal of Consumer Culture, 8(1), 117-145. 
Dastrup, S. R., Zivin, J.G., Costa, D., \& Kahn, M. (2012). Understanding the solar home price premium: Electricity generation and "green" social status. European Economic Review, 56(5), 961-973.

De Groot, J., \& Steg, L. (2009). Mean or green? Values, morality and environmental significant behavior. Conservation Letters, 2 (2), 61-66.

De Groot, J., Thogersen, J., \& Schubert, I. (2016). Morality and green consumer behaviour: a psychological perspective. In: D. Shaw, M. Carrington \& A. Chatzidakis. (Eds.), Ethics and Morality in Consumption (pp. 57-74). London, UK: Routledge.

Degrazia, D. (1998). Suffering. In The Routledge Encyclopedia of Philosophy. Taylor and Francis. Retrieved 10 Aug. 2017, from https://www.rep.routledge.com/articles/thematic/suffering/v-1. doi:10.4324/9780415249126L100-1

Denscombe, M. (2014). The Good Research Guide: For Small-scale Social Research Projects. Maidenhead: McGraw-Hill Education.

Friedman, M. (1991). The Practice of Partiality. Ethics, 101(4), 818-835.

Goodin, R. E. (1986). Protecting the vulnerable: A re-analysis of our social responsibilities. Chicago: University of Chicago Press.

Goodman, D., \& Goodman, M. (2001) Sustaining Foods: Organic Consumption and the Socio-Ecological Imaginary. In: M. Cohen and J. Murphy (Eds.), Exploring Sustainable Consumption: Environmental Policy and the Social Sciences (pp. 97-119). Oxford: Elsevier.

Goodman, M. (2004). Reading fair trade: political ecological imaginary and the moral economy of fair trade foods. Political Geography, 23(7), 891-915.

Gopaldas, A. (2014). Marketplace sentiments. Journal of Consumer Research, 41(4), 995-1014.

Gould, N. (2003). Fair Trade and the consumer interest: a personal account. International Journal of Consumer Studies, 27(4), 341-345.

Harris, J. (1980). Violence and Responsibility. London: Routledge \& Kegan Paul.

Harrison, R., Newholm, T., \& Shaw, D. (2005). Introduction. In: R. Harrison, T. Newholm \& D. Shaw (Eds.), The Ethical Consumer, (pp. 1-8). London: SAGE.

Heath, T., O’Malley, L., Heath, M., \& Story, V. (2016). Caring and conflicted: Mothers' ethical judgments about consumption. Journal of Business Ethics, 136(2), 237-250. 
Held, V. (2006). The ethics of care: personal, political, and global. Oxford: Oxford University Press.

Jackson. P., Ward, N., \& Russell, P. (2009). Moral economies of food and geographies of responsibility. Transactions of the Institute of British Geographers, 34(1), 12-24.

John, A., Klein, J., \& Smith, N. (2002). Exploring motivations for participation in a consumer boycott. Advances in Consumer Research, 29(1), 363-369.

Johnson, M. (1993). Moral imagination. Chicago: University of Chicago Press.

Kahane, G., \& Savulescu, J. (2012). The concept of harm and the significance of normality. Journal of applied philosophy, 29(4), 318-332.

Lawler, S. (2008). Identity. Cambridge, UK: Polity Press.

Lee, R. (2000). Shelter from the storm? Geographies of regard in the worlds of horticultural consumption and production. Geoforum, 31(2), 137-157.

Lekakis, E. (2013). Coffee Activism and the Politics of Fair Trade and Ethical Consumption in the Global North. [Basingstoke]: Palgrave Macmillan.

Littler, J. (2009). Radical Consumption: Shopping for Change in Contemporary Culture. Maidenhead: Open University Press.

Massey, D. (2004). Geographies of Responsibility. Geografiska Annaler B, 86(1), 5-18.

McEwan, C., \& Goodman, M. K. (2010). Place geography and the ethics of care: introductory remarks on the geographies of ethics, responsibility and care. Ethics, Place and Environment, 13(2), 103-112.

Moisander, J. (2007). Motivational complexity of green consumerism. International Journal of Consumer Studies, 31 (4), 404-409.

Moisander, J. \& Pesonen, S. (2002). Narratives of sustainable ways of living: constructing the self and the other as a green consumer. Management Decision, 40(4), 329-342.

Newholm, T. (2005). Case studying ethical consumers' projects and strategies. In: R. Harrison, T. Newholm \& D. Shaw (Eds.), The Ethical Consumer, (pp. 107-124). London: SAGE. Patton, M. (2001). Qualitative Research and Evaluation Methods. Thousand Oaks, Calif.: Sage Publications.

Regan, T. (1983). The Case for Animal Rights. Berkeley: University of California.

Rest, J. (1994). Background: theory and research. In: J. Rest \& D. Narvaez (Eds.), Moral development in the professions, (pp. 1-26). Hillsdale: Erlbaum. 
Shaw, D. (2007). Consumer voters in imagined communities. International Journal of Sociology and Social Policy, 27(3/4), 135-150.

Shaw, D., \& Shiu, E. (2003). Ethics in consumer choice: a multivariate modelling approach. European Journal of Marketing, 37(10), 1485-1498.

Shaw, D., Carrington, M., \& Chatzidakis, A. (Eds.). (2016). Ethics and Morality in Consumption: Interdisciplinary Perspectives (Vol. 8). Routledge.

Shaw, D., McMaster, R., \& Newholm, T. (2013). A visualisation of care in ethical consumption. In: SCORAI 2013: The Future of Consumerism and Well-Being in a World of Ecological Constraints, Worcerster, MA, USA, 12-14 June 2013.

Smith, C. (1990). Morality and the Market: Consumer Pressure for Corporate Accountability. London: Routledge.

Smith, D. (1998a). Geography and moral philosophy: Some common ground. Philosophy \& Geography, 1(1), 7-33.

Smith, D. (1998b). How far should we care? On the spatial scope of beneficence. Progress in Human Geography, 22(1), 15-38.

Smith, D. (2000). Moral geographies: ethics in a world of difference. Edinburgh: Edinburgh University Press.

Soper, K. (2008). Alternative hedonism, cultural theory and the role of aesthetic revisioning. Cultural Studies, 22(5), 567-587.

Stueber, K. (2016). Empathy and the imagination. In: A. Kind (Ed.), The Routledge Handbook of Philosophy of Imagination. New York: Routledge.

Thompson, C., Pollio, H., \& Locander, W. (1994). The spoken and the unspoken: A hermeneutic approach to understanding the cultural viewpoints that underlie consumers' expressed meanings. Journal of Consumer Research, 21(3), 432-453.

Timmons, M. (2002). Moral theory. Lincoln: Rowman \& Littlefield Publishers Inc.

Triodos Bank. (2016). Ethical Consumer Markets Report. [online] Available at: http://www.ethicalconsumer.org/portals/0/downloads/ethical\%20consumer\%20markets\%20repo rt\%202016.pdf [Accessed 18 Apr. 2017].

Varul, M. Z., \& Wilson-Kovacs, D. (2008). Fair Trade Consumerism as an Everyday Ethical Practice-A Comparative Perspective. An ESRC-Funded Research Project, University of Exeter. 
Vetlesen, A. (1993). Why does proximity make a moral difference? Coming to terms with lessons learned from the Holocaust. Praxis International, 12(4), 371-386.

Zadek, S., Lingayah, S., \& Forstater, M. (1998). Social labels: Tools for ethical trade. London: New Economics Foundation. 